Version accepted for publication and published in International Journal for Academic Development, 14(1), pp. 83-85.

Research Note

\title{
Why History? Why Now? Multiple accounts of the emergence of academic development
}

Barbara Grant, The University of Auckland

Alison Lee, University of Technology, Sydney

Sue Clegg, Leeds Metropolitan University

Catherine Manathunga, University of Queensland

Mark Barrow, The University of Auckland

Peter Kandlbinder, University of Technology, Sydney

Ian Brailsford, The University of Auckland

David Gosling, Higher Education Consultant, UK

Margaret Hicks, University of South Australia

\begin{abstract}
More than forty years after its beginnings, academic development stands uncertainly on the threshold of becoming a profession or discipline in its own right. While it remains marginal to the dominant stories of the university, it has become central to the institution's contemporary business. This Research Note describes an enquiry that uses a multiple histories approach to explore the emergence of academic development in three national sites. Our intention is to provoke a more critical engagement with academic development's current forms and future possibilities.
\end{abstract}

Keywords: academic development, traditional history, oral history, critical histories

As a distinct field of practice, academic development emerged at a point of major policy change in the history of western universities. After World War II, significant pressures meant that traditional ways of operating, including modes of teaching and learning, came under question. Throughout the 1960s small numbers of academics began to work together to build knowledge and skill in teaching undergraduate students. From these relatively informal beginnings, and via different pathways, academic development was gradually incorporated into the formal structures and functions of universities. Academic development's profile may be, in important ways, symptomatic of the changing fortunes of the university. Hence a careful engagement with the past of this 'profession' offers an opportunity to examine what have come to be taken-for-granted aspects of university work.

While academic development has been mapped already in various ways (see, for example, Eggins \& Macdonald, 2003; Elvidge, 2004; Land, 2004; Sorcinelli et al. 2006), there is yet no systematic study of the varied trajectories that led to its creation as a field. Our purpose is to do just this by exploring its emergence in Aotearoa New Zealand, Australia, and the United Kingdom through interviews with key players alongside archival research. A multiple histories approach - including traditional, oral and critical modes of history-making - seems most valuable because each offers different insights into academic development's present. Moreover, such research exemplifies the interdisciplinarity that is a fertile feature of academic development and that we find within our own research team.

The traditional history part of our research centres on archival research, in particular examining university records. This methodology foregrounds evidence 
(quotations) from primary sources as the starting points for history, rather than unifying theories or themes. Aiming for the strictest level of impartiality possible, the traditional historian tends to privilege authoritative written documents as the most reliable sources of what happened, and why, in days gone by. In practice, these scholars home in on 'factual' details as recorded in such sources, typically found in public or semi-public archives. Most commonly, they begin by compiling a list of secondary sources that, in turn, help them to identify the key primary ones. They will search, perhaps with the help of specialist librarians and archivists, to locate available and accessible archives. Then they will make a judgment as to which of those archives might be the richest sources of fact and insight into the topic or event under enquiry. Such archives become subject to forensic review. For example, in constructing a narrative of the emergence of one centre, our colleague initially pursued three kinds of documents: the centre's research reports, the institution's in-house newspaper across the decade in which centre emerged, and the centre's annual reports in the first 15 years of its existence (Brailsford, 2008).

In contrast, the oral history mode attends to informal, first-hand accounts of particular events and experiences and the way in which such accounts supplement, even interrupt, the official records. The methodology of oral history not only captures stories of individuals' experiences that are unlikely to be written anywhere else but also, if carefully unpacked, gives 'insight into the meaning of the individual's experiences: not just what happened' (Green, 2004, p.12). Here the research team's interests coincided with those of the Higher Education Research and Development Society of Australasia that funded an oral history study of the emergence of academic development in Australia as recounted by 12 of its key protagonists (Lee, Manathunga \& Kandlbinder, 2008) who are also HERDSA Life Members. Their reminiscences have been captured through lengthy semi-structured interviews in which they were asked about their career history, their involvement in the establishment and consolidation of academic development, their definitions of academic development and views of its maturation as a field of practice, and their identification of key institutional sites and people.

As our research proceeds, we will also produce a series of diverse critical histories that aim to be partial, provisional and political (rather than to be disinterested, as in traditional history, or to reclaim the personal, as in oral histories). One mode of critical history will be genealogy, as developed by Michel Foucault (1984), which seeks to inform understandings of how the present has come to take the form and shape it has, in particular how our self-understandings have come about. A genealogical study of academic development invites an examination of our implicit assumptions and beliefs about the 'natural' or necessary character of current practices in academic development. Genealogical history will be accompanied by post-colonial, critical realist and critical reconstructive readings of the archival and interview material we collect.

Multiple histories arising from different epistemologies will undoubtedly produce tensions, but we see this as a fruitful dissensus. Through offering different interpretations of academic development's emergence, we hope that its past becomes more thoroughly investigated than is currently the case, its future more openly and fully contested, and the stories we tell of its benefits to higher education more open to interpretation and critique.

\section{References}


Brailsford, I. (2008). Why we needed a HERO at the University of Auckland: Academic and staff development in its infancy. Paper presented at the HERDSA Conference, 01-04 July 2008, Rotorua (NZ).

Eggins, H. \& Macdonald, R. (Eds.). (2003). The scholarship of academic development. Buckingham: SRHE and Open University Press.

Elvidge, L., with Fraser, K., Land, R., Mason, C. \& Matthew, B. (Eds.). (2004). Exploring academic development in higher education: Issues of engagement. Cambridge: Jill Rogers Associates Ltd.

Foucault, M. (1984). Nietzsche, genealogy, history. In P. Rabinow, (Ed.), The Foucault Reader (pp. 76-100). London: Penguin.

Green, A. (2004). 'Unpacking' the stories. In A. Green, \& M. Hutching (Eds.), Remembering: Writing oral history (pp.9-24). Auckland: Auckland University Press.

Land, R. (2004). Educational development: Discourse, identity and practice, Buckingham: SRHE and Open University Press.

Lee, A., Manathunga, C. \& Kandlbinder, P. (2008). Making a place: An oral history of academic development in Australia. Milperra, NSW: HERDSA.

Sorcinelli, M.D., Austin, A.E., Eddy, P.L. \& Beach, A.L. (2006). Creating the future of faculty development: Learning from the past, understanding the present. Bolton, MA: Anker Publishing Company. 